LAWRENCE LIVERMORE N A T IO N A L LABORATORY

JWL Calculating

P. Clark Souers

May 4, 2005 
This document was prepared as an account of work sponsored by an agency of the United States Government. Neither the United States Government nor the University of California nor any of their employees, makes any warranty, express or implied, or assumes any legal liability or responsibility for the accuracy, completeness, or usefulness of any information, apparatus, product, or process disclosed, or represents that its use would not infringe privately owned rights. Reference herein to any specific commercial product, process, or service by trade name, trademark, manufacturer, or otherwise, does not necessarily constitute or imply its endorsement, recommendation, or favoring by the United States Government or the University of California. The views and opinions of authors expressed herein do not necessarily state or reflect those of the United States Government or the University of California, and shall not be used for advertising or product endorsement purposes.

This work was performed under the auspices of the U.S. Department of Energy by University of California, Lawrence Livermore National Laboratory under Contract W-7405-Eng-48. 


\title{
JWL Calculating
}

\author{
P. Clark Souers \\ May 2, 2005
}

The following is a list of JWL properties to be sent to Sedat Esen, who is an explosive analyst for a Swedish industrial institute at

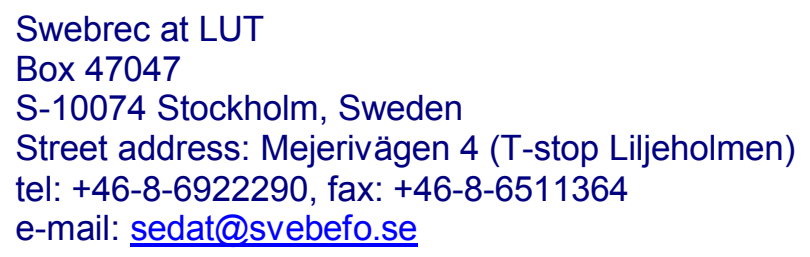

The JWL is a standard equation of state used worldwide to describe the pressure-volume-energy behavior of a detonating explosive. Even so, not many people are very good at working with it. So I list all the various equations that describe how it works, then give one way that the solution can be obtained in an iterative manner.

I have collaborated with Sedat Esen for several years. I am indebted to him for supplying almost all of our collection of dynamite data. He now works with ammonium nitrate/fuel oil, which is another area of interest to us.

\subsubsection{Arithmetic of the JWL Two forms of the JWL}

The three-coefficient JWL equation is

$$
P=A \exp \left(-R_{1} v\right)+B \exp \left(-R_{2} v\right)+\frac{C}{v^{1+\omega}}
$$

The integral is the internal energy

$$
E_{S}=\frac{A}{R_{1}} \exp \left(-R_{1} v\right)+\frac{B}{R_{2}} \exp \left(-R_{2} v\right)+\frac{C}{\omega v \omega}
$$

In our codes, $E_{S}$ is positive and at its maximum at the C-J point (there is no spike with the pure JWL). As the products expand, $E_{S}$ declines toward zero. From Eq. 2 


$$
C=\omega v^{\omega}\left[E_{S}-\frac{A}{R_{1}} \exp \left(-R_{1} v\right)+\frac{B}{R_{2}} \exp \left(-R_{2} v\right)\right]
$$

If we substitute Eq. 3 into Eq. 1, we get

$$
P=A\left[1-\frac{\omega}{R_{1} v}\right] \exp \left(-R_{1} v\right)+B\left[1-\frac{\omega}{R_{2} v}\right] \exp \left(-R_{2} v\right)+\frac{\omega E_{S}}{v}
$$

This is the form hydrocode people like at out Lab, because both energy and pressure enter into it. They like having all three variables confirmed at each step.

\section{$\Gamma$ at the C-J Point}

At the C-j Point, the Rayleigh Line equation is

$$
P_{c j}=\rho_{o} U_{S}^{2}\left(1-v_{c j}\right)
$$

so that

$$
\frac{d P_{C j}}{d v}=-\rho_{O} U_{S}^{2}
$$

Then,

$$
\Gamma_{c j}=-\frac{v d P}{P d v}=\frac{v_{c j}}{1-v_{c j}}
$$

Our Lab's current codes use the C-J parameter of

$$
\text { bhe }=\Gamma_{c j}+1=\frac{1}{1-v_{c j}}
$$

This is used as a rate constant in Program Burn. So that the rate goes as bhe(1-v).

\section{Another Form of the C-J Pressure}


At the C-J point, the internal energy is the sum of the chemical energy $E_{O}$ and the energy of compression, $\mathrm{E}_{\mathrm{C}}$, which is

$$
E_{C}(c j)=\frac{1}{2} P_{c j}\left(1-v_{c j}\right)
$$

so that

$$
E_{S}(c j)=E_{O}+E_{C}(c j)
$$

We now take Eq. 4 and substitute for $E_{s}$ to get

$$
P_{C j}=A\left[1-\frac{\omega}{R_{1} v_{c j}}\right] \exp \left(-R_{1} v_{c j}\right)+B\left[1-\frac{\omega}{R_{2} v_{c j}}\right] \exp \left(-R_{2} v_{C j}\right)+\frac{\omega}{v_{c j}}\left[E_{O}+\frac{1}{2} P_{C j}\left(1-v_{C j}\right)\right]
$$

We solve for $\mathrm{P}_{\mathrm{cj}}$ to get

$$
P_{C j}=\frac{A\left[1-\frac{\omega}{R_{1} v_{c j}}\right] \exp \left(-R_{1} v_{c j}\right)+B\left[1-\frac{\omega}{R_{2} v_{c j}}\right] \exp \left(-R_{2} v_{c j}\right)+\frac{\omega E_{o}}{v_{c j}}}{1-\frac{\omega\left(1-v_{c j}\right)}{2 v_{c j}}}
$$

\section{On the Adiabat}

$E_{o}$ is the total chemical energy present in the explosive but it only comes out in the detonation after the products expand to infinite volume. Along the way, we get out some of the energy at the relative Cylinder test volumes of 2.2, 4.4 and 7.2. So, at some volume v larger than C-J, we have

$$
E_{d}(v)=\left[E_{S}\left(v_{c j}\right)-E_{S}(v)\right]-E_{C}(c j) .
$$


At the C-J point, $E_{d}$ equals $-E_{c}$ and is negative in our codes. At infinite volume, $E_{s}(v)$ is zero and $E_{d}(\infty)=E_{0}$, the largest positive number. At somewhere around $v \sim 0.91$, the crossover from negative to positive detonation energy occurs. We substitute the C-J quantities in Eq. 10 into Eq. 13 to get

$$
E_{d}(v)=E_{O}-E_{s}(v)
$$

We substitute Eq. 2 to get

$$
E_{d}(v)=E_{o}-\left[\frac{A}{R_{1}} \exp \left(-R_{1} v\right)+\frac{B}{R_{2}} \exp \left(-R_{2} v\right)+\frac{C}{\omega v}\right]
$$

\section{Rayleigh Line}

If we differentiate Eq. 1 we have

$$
\frac{d P}{d v}=-A R_{1} \exp \left(-R_{1} v\right)-B R_{2} \exp \left(-R_{2} v\right)-\frac{(1+\omega) C}{v^{2+\omega}}
$$

We combine this with Eq. 6 to get the detonation velocity

$$
U_{S}=\left\{\frac{1}{\rho_{O}}\left[A R_{1} \exp \left(-R_{1} v\right)+B R_{2} \exp \left(-R_{2} v\right)+\frac{(1+\omega) C}{v^{2+\omega}}\right]\right\}^{1 / 2} .
$$

\subsubsection{New Calculation Method}

Start with $\rho_{\mathrm{o}}, R_{2}, R_{1}, \omega$, and $E_{o}$ which stay constant. Also, we start with initial values of $U_{s}$, $E_{d}(2.2), E_{d}(4.4)$ and $E_{d}(7.2)$ which should not change much during the calculation. Add rough values for $A, B$ and bhe, which will be calculated and could change considerably. Then we go through these 7 steps.

$$
v_{c j}=1-\frac{1}{b h e}
$$




$$
\begin{aligned}
& P_{C j}=\frac{A\left[1-\frac{\omega}{R_{1} v_{C j}}\right] \exp \left(-R_{1} v_{c j}\right)+B\left[1-\frac{\omega}{R_{2} v_{c j}}\right] \exp \left(-R_{2} v_{c j}\right)+\frac{\omega E_{O}}{v_{c j}}}{1-\frac{\omega\left(1-v_{C j}\right)}{2 v_{c j}}} \\
& C=\omega v^{\omega}\left[E_{S}-\frac{A}{R_{1}} \exp \left(-R_{1} v\right)+\frac{B}{R_{2}} \exp \left(-R_{2} v\right)\right] \\
& E_{d}(v)=E_{O}-\left[\frac{A}{R_{1}} \exp \left(-R_{1} v\right)+\frac{B}{R_{2}} \exp \left(-R_{2} v\right)+\frac{C}{\omega v \omega}\right] \text { at } v=2.2,4.4 \text { and } 7.2 \\
& U_{S}=\left\{\frac{1}{\rho_{O}}\left[A R_{1} \exp \left(-R_{1} v\right)+B R_{2} \exp \left(-R_{2} v\right)+\frac{(1+\omega) C}{v^{2+\omega}}\right]\right\}^{1 / 2} \\
& P_{c j}(a)=\rho_{o} U_{S}^{2}\left(1-v_{c j}\right) \\
& P_{c j}(b)=A \exp \left(-R_{1} v_{c j}\right)+B \exp \left(-R_{2} v_{c j}\right)+\frac{C}{v_{c j}^{1+\omega}}
\end{aligned}
$$

We define these $\%$-change comparisons

$$
\begin{aligned}
& \alpha=\frac{100\left[U_{S}-U_{S}(\text { inital })\right]}{U_{S}(\text { inital })} \\
& \beta=\frac{100\left[P_{C j}(a)-P_{C j}(b)\right]}{P_{C j}(b)}
\end{aligned}
$$




$$
\begin{gathered}
\delta(v)=\frac{100\left[E_{d}(v)-E_{d}(v, \text { inital })\right]}{E_{d}(v, \text { initial })} \text { at } v=2.2,4.4 \text { and } 7.2 \\
\delta=\frac{\delta(2.2)+\delta(4.4)+\delta(7.2)}{3}
\end{gathered}
$$

We now enter a loop of repetitive calculations, in which we change the three variables one after another using these algorithms

$$
\begin{aligned}
& \text { bhe }(\text { new })=\text { bhe }(\text { old })+0.01 \delta \\
& \mathrm{A}(\text { new })=(1-0.03 \alpha) \mathrm{A}(\text { old }) \\
& \mathrm{B}(\text { new })=(1+0.05 \beta) \mathrm{B}(\text { old })
\end{aligned}
$$

We go through the 7-steps again that we listed above after each variable change so we have three complete calculations on each loop. The process is repeated for 50 cycles or until

$$
\alpha, \beta \leq 0.0002
$$

where these limits are arbitrary. The new JWL is balanced within the errors of Eq. 25. Like all non-linear fitters, the initial guesses have to reasonably close to the final answer. It is also possible to get an unphysical result, which usually appears in the form of a negative value for $B$. Because of this, it is usually best to make a large change in small increments.

People are getting fussier with their JWL's and are starting not to like the round-off errors. To reproduce exactly a JWL, we really need to save the three adiabat energies. In saving all these numbers, it inconvenient to have numbers calculated out to a huge number of decimal places. An improvement may be made by rounding off the $E_{d}(v)$ values to 5 decimal places and recalculating. 